3 Kirigia JM, Gbary AR, Muthuri LK, Nyoni J, Seddoh A. The cost of health professionals' brain drain in Kenya. BMC Health Serv Res 2006; 6: 89

4 International Fund for Agricultural Development (IFAD). Investing in Rural People in The Gambia. IFAD, 2016.

5 World Bank. Poverty \& Equity Brief: Africa Western \& Central. The Gambia. World Bank Group, 2020 (https://databank.worldbank. org/data/download/poverty/987B9C90-CB9F-4D93-AE8C 750588BF00QA/SM2020/Global_POVEQ_GMB.pdf).

6 Republic of The Gambia Department of State for Health and Social Welfare. The Gambia Mental Health Strategic Plan 20072012. Republic of The Gambia, 2007

7 Gale NK, Heath G, Cameron E, Rashid S, Redwood S. Using the framework method for the analysis of qualitative data in multi-disciplinary health research. BMC Med Res Methodol 2013; 13: 117.

8 Kretzschmar I, Nyan O, Mendy AM, Janneh B. Mental health in the Republic of The Gambia. Int Psychiatry 2012; 9(2): 38-40.

9 Irankunda P, Heatherington L, Fitts J. Local terms and understandings of mental health problems in Burundi. Transcult Psychiatry 2017; 54: 66-85.
10 Ae-Ngibise K, Cooper S, Adiibokah E, Akpalu B, Lund C, Doku V, et al 'Whether you like it or not people with mental problems are going to go to them': a qualitative exploration into the widespread use of traditional and faith healers in the provision of mental health care in Ghana. Int Rev Psychiatry 2010; 22: 558-67.

11 Jack-Ide IO, Uys L. Barriers to mental health services utilization in the Niger Delta region of Nigeria: service users' perspectives. Pan Afr Med J 2013; 14: 159.

12 Zingela Z, van WS, Pietersen J. Use of traditional and alternative healers by psychiatric patients: a descriptive study in urban South Africa. Transcult Psychiatry 2018; 56: 146-66.

13 Ohaeri JU. Caregiver burden and psychotic patients' perception of social support in a Nigerian setting. Soc Psychiatry Psychiatr Epidemiol 2001; 36: 86-93.

14 Gureje O, Lasebikan VO, Ephraim-Oluwanuga O, Olley BO, Kola L. Community study of knowledge of and attitude to mental illness in Nigeria. Br J Psychiatry 2005; 186: 436-41.

15 Muela SH, Mushi AK, Ribera JM. The paradox of the cost and affordability of traditional and government health services in Tanzania. Health Policy Plan 2000; 15: 296-302.

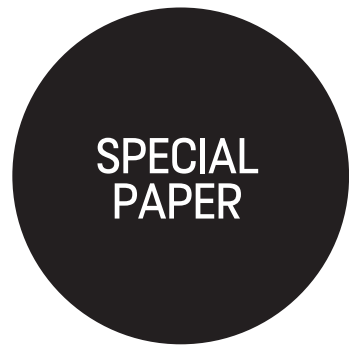

\title{
Mental Health Gap Action Programme training in Nigeria: reflections for progressive learning among primary care workers
}

\author{
Alvina Ali ${ }^{1} \odot$ and Nandini Chakraborty ${ }^{2} \odot$
}

${ }^{1}$ Child And Adolescent

Psychiatrist, Child And Adolescent Mental Health Unit, Leicestershire Partnership NHS Trust, UK, email: alvina.ali@leicspart.nhs.uk

${ }^{2}$ Consultant Psychiatrist, PEIR ${ }^{2}$ Consultant Psychiatrist, PEIR
Team, Leicestershire Partnership NHS Trust, UK

Keywords. Mental health; training; primary care.

First received 20 Oct 2020 Final revision 12 Apr 2021 Accepted 14 Jun 2021

\section{doi:10.1192/bji.2021.32}

(c) The Author(s), 2021. Published by Cambridge University Press on behalf of the Royal College of

Psychiatrists. This is an Open

Psychiatrists. This is an Open
Access article, distributed under the terms of the Creative Commons Attribution licence (http://creativecommons.org/ licenses/by/4.0/), which permits unrestricted re-use, distribution, and reproduction in any any medium provided the original work is properly cited.
In the majority of low- and middle-income countries, mental healthcare is delivered by primary care workers. Often, they are the only contact for patients and their families. Although their knowledge base can be limited, they are expected to manage complex cases with few resources. The authors describe their experience of partnership with mental health centres set up by the Nigeria Health Care Project, and training their primary care workers based on the World Health Organization's Mental Health Gap Action Programme. Although the programme was very effective in helping to upskill their knowledge and experience, a need for continued professional development was highlighted. Based on their feedback, multiple evidence-based options are explored, including the use of remote learning and social media (increased significantly around the world because of the COVID-19 pandemic), to help primary care workers improve their knowledge base and maintain their competencies with the limited resources available.
A gap in mental health service provision is recognised as a global health problem. People with mental illness or a learning disability are some of the most stigmatised and abused people in society. In recent years, mental healthcare has shifted increasingly toward early intervention and management in community settings rather than in hospitals. However, many low- and middle-income countries do not have the services or resources to respond to the huge need that exists.

In the majority of countries primary care workers are the first, or in many cases the only, clinical contact available for patients and carers. Studies show that the limited knowledge among health care professionals can be a barrier to providing optimal care in primary care settings. ${ }^{1}$ Often, the treatment provided by them is symptom-based, without an understanding of the diagnostic formulation based on the biopsychosocial model. Hence, clinicians working in rural settings tend to require more diverse skill sets to manage complex conditions with very little resources. ${ }^{1}$

Leicestershire Partnership NHS Trust joined the NHS International Links scheme in 2004, with the aim of improving and strengthening mental health and learning disability care outside 
the UK and providing opportunities for staff to develop and expand their skills and knowledge. The Nigeria Health Care Project (NHCP) is part of that link.

Nigeria, called the 'Giant of Africa', is the seventh most populous country in the world. Up to $20-30 \%$ of population suffer from mental disorders. ${ }^{2}$ There are more than 34000 health facilities, $66 \%$ of which were owned by the three tiers of government (federal, state and local government authority). The secondary- and tertiary-level health facilities are mostly found in urban areas, whereas rural areas are predominantly served by primary health care facilities. Problems regarding equity, accessibility, affordability and efficiency of mental health services (which are the overall policy objectives of the revised national health policy of Nigeria) still persist in the country.

\section{The NHCP}

The project was launched in April 1992 to revive the work of the Wesley Guild and medical mission in Nigeria, which began at Ilesha Hospital in 1912. ${ }^{3}$ Beginning with just two (centres) projects in 1992, they are currently involved in funding 16 projects. They provide assessment and treatment for individuals who have become homeless because of mental health problems, and act as rehabilitation centres for residents. The teams are led by a qualified community psychiatric nurse (CPN) and community health workers on each site. ${ }^{3}$

\section{Mental Health Gap Action Programme}

The training provided was based on the World Health Organization's Mental Health Gap Action Programme (mhGAP), ${ }^{4}$ which plays a key role in 'scaling up services' across the developing world. It provides competency-based training aimed to build on the existing knowledge and skills of clinicians mainly in a primary care setting.

We delivered mhGAP version 2.0 training to two groups of multidisciplinary clinicians who were part of the NHCP. One group received this training for first the time, and the second group received it as a refresher to revise and reinforce knowledge gained in previously attended training. We used a variety of techniques, such as class-based learning, role-plays and case-based discussions, to help them develop these competencies. Feedback on learning was collected and reflected on at the end of the training, from both groups.

\section{Feedback and reflection}

Both groups were excellent examples of CPN-led projects in the community. There was a high level of interest in learning in both groups. In the posttraining feedback, participants reported that it helped them to develop a more reflective mental health practice, becoming more aware of mental health issues, and they were able to integrate new knowledge and skills into their work.
For the group receiving refresher training, it was evident that the topic-based discussions were at a more sophisticated level and seemed to be more management focused. They reported an improved awareness of the need for preventative work at schools and community, especially on addiction and suicide. For the group receiving training for the first time, the focus remained more on improving their assessment skills and general mental health awareness.

There was a difference in the knowledge and skills of different professional groups (CPN and primary care workers). It was clear that formal education at an undergraduate level is not enough to enable primary care workers to continue to manage day-to-day challenges over time, and especially those related to mental health. They both expressed a need for further training as part of their continuous professional development, to allow them to support the rapidly changing mental health needs of the population they covered. There was no existing concept of peer supervision or staff team days to encourage mutual learning.

We explored ideas of peer support and supervision/further training from experienced clinicians (e.g. psychiatrists) in the field. Although both groups were keen to develop the idea of peer support, supervision from experienced psychiatrists and other experts to promote further learning was recognised as a challenge. The main reason was the remote location of their bases and long distance from larger centres where psychiatrists were present, which made it logistically difficult for this option to be implemented. A need to think of more creative accessible solutions was highlighted.

\section{Discussion}

It is known that health promotion and education in the general public and care workers significantly help in healthcare management, especially in developing countries. Primary care workers can play an important and effective role in promoting healthcare, particularly if they are well informed. Previous studies have shown that the attitudes of community volunteers toward people with mental illness improve with educational programmes, which leads to improved treatment and care of individuals who are mentally ill. ${ }^{5}$ The question is how and by whom this can be done effectively, ensuring continuity and sustainability over the long term. Training all staff at once without disrupting clinical services in an already resource-stretched area was impossible. The reason for choosing mhGAP training was also because its framework provides the relevant knowledge and encourages building networks for further supervision.

Psychiatrists can play an important role in upskilling non-medical staff through regular training, teaching and supervision. However, most psychiatrists practicing in low- and middle-income countries are located in university hospitals in urban 
centres. Majority of them are insulated from the larger community that they serve, and often lack an understanding of patients' living conditions and needs in rural areas. ${ }^{6}$ CPN-led projects like NHCP have proved to be very effective in bridging that gap. However, there is need for secondary care to link and support primary care clinicians, ensuring their continuous professional development over time. It appears that there are significant challenges in the current processes to link up with the regional- and state-level psychiatric units (as demonstrated in our group setting) for further training and supervision. Also, when support from regional units is offered, it can be $a d$ hoc and resource limited.

The other challenges that we found, such as diversity, scope and complexity of primary healthcare and limited infrastructure available to support the population, were very similar to those reported in other projects of this nature. With the COVID-19 pandemic, the availability of such face-to-face learning opportunities seems more distant. However, the pandemic-induced surge in the use of social media has also lead to the use of very innovative ideas across the world, to exchange knowledge and improve our continuous professional development.

There is evidence that many creative ideas have also been tried and implemented successfully even before the pandemic. Some of the following have proven to be very effective and are probably more achievable now, with the use of social media platforms.

\section{Peer learning}

This is cost-effective and improves social connectedness of the participants. It enables them to learn new skills and share good practices, which in turn helps to increase their sense of selfworth and improve their relationships with others. $^{7}$

\section{Experiential learning}

Experiential learning is defined as learning achieved through the appropriate use of current experience. It is one of the educational models that can be used to achieve CPD and improve health service delivery. ${ }^{8}$

\section{Use of digital media/e-learning}

e-Learning is being increasingly used in healthcare education. There is growing evidence that e-learning produces broadly similar outcomes as face-to-face education. However, there is burgeoning interest in how healthcare professionals learn online, and how they transfer their learning into clinical practice. Many countries, like Australia, Nepal and India, have already used digital platforms as an effective way of upskilling clinicians who work in rural settings. The issue is the availability and support in using it appropriately. ${ }^{9}$ There have been trials of using video lectures and on-site skills training successfully, to address the limitations of a conventional training model. The key is that it is accessible and able to transfer the clinical knowledge required.

\section{Interprofessional programmes}

Interprofessional programmes teach and train workers to work together to manage the chronic and complex patient groups effectively. As Church et al indicated, there are many programmes tried and proven to be of benefit to primary care workers, in many countries. ${ }^{10}$ Psychiatry trainees could play a crucial role here, if rotation to rural areas become mandatory part of their training. Support from the government and psychiatrist associations is essential in implementing this. There are obstacles seen in the form of a lack of flexibility in training rotations, isolation from peers and insufficient support when relocating. ${ }^{11}$

There is also a need to develop educational opportunities for trainees placed on these sites, and explore the necessary adaptation of existing curricula to provide optimal learning in rural and remote environments. ${ }^{12}$

All methods described above have a good evidence base, and all have their own advantages and limitations. However, if adapted realistically, they could all be potentially effective.

\section{Conclusions}

Our experience demonstrates that the mhGAP training programme not only improved the knowledge base and skills, but also promoted the social connectedness, of different mental healthcare teams in various settings. As Joynes et $\mathrm{al}^{13}$ state, maximising informal learning opportunities and removing barriers to doing so should be a priority for primary care practitioners, managers and educators. The idea for groups to set up peer supervision would certainly help to enhance their mutual support over the long term. We also agree that there is a need for advocacy for them to sustain this support, and accept the fact that there are clear challenges surrounding this. Creative use of social media could be a possible solution, but internet connectivity could still be a problem in such areas. Despite this, there is a huge potential (as demonstrated during the COVID-19 pandemic) for further training and remote supervision through this platform, which is worth future exploration.

\section{Author contributions}

Both authors are substantial contributors to the conception, documented work and write-up of this paper.

\section{Funding}

The training described received no specific grant from any funding agency in the public, commercial or not-for-profit sectors.

\section{Declaration of interest}

None. 


\section{References}

1 Manjunatha N, Kumar C, Math S, Thirthalli J. Designing and implementing an innovative digitally driven primary care psychiatry program in India. Indian J Psychiatry 2018; 60(2): 236-44.

2 Suleiman DE. Mental health disorders in Nigeria: a highly neglected disease. Ann Nigerian Med 2016; 10: 47-8.

3 Nigeria Health Care Project (NHCP). Projects. NHCP, 2021 (https://nhcp.org.uk/projects).

4 World Health Organization (WHO). mhGAP: Mental Health Gap Action Programme: Scaling Up Care for Mental, Neurological, and Substance Use Disorders. WHO, 2008 (http://www.who.int/ mental_health/mhgap_final_english.pdf).

5 Abayomi O, Adelufosi AO, Olajide A. Changing attitude to mental illness among community mental health volunteers in south-western Nigeria. Int J Soc Psychiatry 2013; 59(6): 609-12.

6 Giel R. Psychiatry in developing countries. Psychiatr Ann 1978; 8 (6): $315-20$

7 Marcus TS, Reji E, Ngcobo S. Peer-learning reviews to improve Gauteng community-oriented primary care: findings from AitaHealth ${ }^{\mathrm{TM}}$-enabled ward-based outreach teams. Afr ] Primary Health Care Fam Med 2020; 12(1): e1-10.
8 Allodola VF. The effects of educational models based on experiential learning in medical education: an international literature review. Tutor 2014; 14: 23-49.

9 Acharya B, Tenpa J, Basnet M, Hirachan S, Rimal P, Choudhury N, et al. Developing a scalable training model in global mental health: pilot study of a video-assisted training program for generalist clinicians in rural Nepal. Glob Ment Health 2017; 4: e8.

10 Church EA, Heath OJ, Curran VR, Bethune C, Callanan TS, Cornish PA. Rural professionals' perceptions of interprofessional continuing education in mental health. Health Soc Care Community 2010; 18(4): 433-43.

11 De Moore G, Smith K, Earle MB. From golden beaches to the heartland: reflections of NSW rural trainees. Australas Psychiatry 2006; 14(1): 72-5.

12 Berntson A, Goldner E, Leverette J, Moss P, Tapper M, Hodges B. Psychiatric training in rural and remote areas: increasing skills and building partnerships. Can J Psychiatry 2005; 50(9): 1-8.

13 Joynes V, Kerr M, Treasure-Jones T. Exploring informal workplace learning in primary healthcare for continuous professional development. Educ Prim Care 2017; 28(4): 216-22.

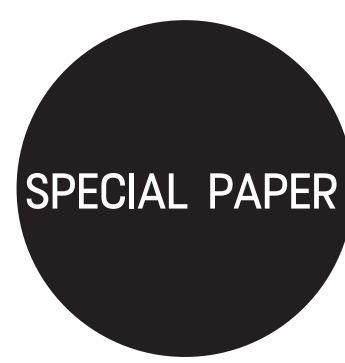

Associate Professor of Psychiatry, Government Medical College, Thiruvananthapuram, India. Email kriyalak2015@gmail.com

Keywords. Mindfulness; Indian psychotherapy; Kerala; Indian

First received 26 Sep 2020 Accepted 26 Apr 2021

doi:10.1192/bji.2021.33

(c) The Author(s), 2021. Published by Cambridge University Press on behalf of the Royal College of Psychiatrists. This is an Open Access article, distributed under the terms of the Creative Commons AttributionCons NonCommercial-ShareAlike licence (http://creativecommons. org/licenses/by-nc-sa/4.0/), which permits non-commercial re-use, distribution, and reproduction in any medium, provided the same Creative Commons licence is included and the original work is properly cited. The written permission of Cambridge University Press must be obtained for commercial re-use.

\title{
Chronicle of an Indian psychiatrist's mindfulness journey retold
}

\author{
Sivasubramoney Krishnan 10
}

This article describes the author's discovery of mindfulness and its method and describes the bias against mindfulness even at the beginning of the 21 st century. The short essay also throws light on recent developments in mindfulness training and practice in the world and in the state of Kerala in South India.

'Sir, the Professor is on the way...' a resident ran hurriedly into the room to inform.

The meditation session in progress ceased. The projector opened its eyes onto the screen in front, tinted yellow by oldness. Slides on bipolar disorder began to roll on. The professor witnessed the class in progress with satisfaction.

The year was 2001. The venue, Mental Health Centre of the State. The attendees were about fifty nursing students who had come for their psychiatry training from various nursing colleges in the state. The class was being taken by a young psychiatrist (me!), who wanted to walk through the pathways of mental healthcare less travelled by many. The topic was mindfulness, something considered veiled, shadowy and lewd by many mental health professionals in my part of the country.

It was in 2005 that I was first exposed to the drizzle of mindfulness, during the final year of my residency programme. Before that, for the previous 8 years, I was serving as the junior-most faculty in the Department of Psychiatry of my institution (my title was Lecturer in Psychiatry, the qualification for which was an MBBS (Bachelor of Medicine and Bachelor of Surgery), the basic medical course in India). Way back in 1976 in the stress clinic of Massachusetts University, Jon Kabat Zinn had started the mindfulness revolution that in due course came to be called mindfulness-based stress reduction. ${ }^{1}$ It was generally discussed that India was the land where mindfulness originated. Yet there were only a few centres in India (unknown to me and most other people) to impart training on this. Curious about and fascinated by the meditations of Jon Kabat Zinn, Emeritus Professor of Medicine at the University of Massachusetts Medical School, and the world of his classic masterpiece Full Catastrophe Living, ${ }^{2}$ I journeyed into the world engulfed by a little book - The Miracle of Mindfulness - penned by Thich Nhat Hanh, a Vietnamese monk. ${ }^{3}$ By the time I started to lay my initial steps, mindfulness, the Eastern contemplative practice rooted in Buddhism, had been reasonably well integrated into the fields of medicine and behavioural health, grounded in Western science. ${ }^{4}$ Still, I was reading about and attempting to practise a method that was equated with having schizophrenia among professionals in my part of the country.

Jon Kabat Zinn defined mindfulness as the awareness cultivated by non-judgemental, open, 